\title{
Feasibility Of Removable Partial Dentures In Saveetha Dental College
}

Research Article

S. Sivaharini ${ }^{1}$, Rakshagan $^{2 *}$, Vivek Narayan ${ }^{3}$

${ }^{1}$ Saveetha Dental College And Hospitals, Saveetha Institute Of Medical and Technical Sciences, Saveetha University, Chennai, 600050, India.

${ }^{2}$ Senior Lecturer, Department of Prosthodontics, Saveetha Dental College and Hospitals, Saveetha Institute Of Medical And Technical Sciences, Saveetha University, Chennai, India.

${ }^{3}$ Senior Lecturer, Department of Oral Medicine, Saveetha Dental College and Hospitals, Saveetha Institute Of Medical And Technical Sciences, Saveetha University, Chennai, India.

\section{Abstract}

The aim of the present study is to evaluate the feasibility of the removable partial dentures in Saveetha Dental College. A total of 3725 patients with partial edentulism were used for this study. Records of patients in need of removable partial dentures were collected from 86000 patient records involving the time period of June 2019 to March 2020. The data was imported using SPSS analysis software. The records were formulated into an excel sheet. Within the limits of the study, the most common prevalence of having removable dentures in males is more than females in Saveetha Dental College. The 50-80 years of age group have more prevalence. With carefully planned prosthodontic treatment and adequate maintenance of oral and denture hygiene, we can prevent periodontal diseases.

Keywords: Denture; Prosthesis; Periodontal Disease; Removable Partial Dentures; Abutment Teeth.

\section{Introduction}

Removable partial dentures play an important role in periodontal health. Glickman in 1948 reported that from a periodontalpoint of view, fixed prostheses are most suitable for the replacement of missing teeth [13]. Some patients are unable to afford treatment with implants due to anatomical or economic reasons, therefore removable dentures can be considered a simple, noninvasive, and relatively cheap treatment option for replacement of missing teeth [8]. Interim removable dentures are used [1] to establish a new occlusal relationship or occlusal vertical dimension; [2] to condition teeth and ridge tissue for optimum support of the definitive removable partial denture that will follow. Interim removable partial dentures may be used as occlusal splints like the cast or resin occlusal splints that are used on natural teeth [22].

A removable partial denture enables the restoration or improvement of 4 oral functions namely aesthetics, mandibular stability, mastication, and speech. However, wearing a removable partial denture should not interrupt with oral comfort $[7,18,11]$.

Removable partial dentures are unique compared to prostheses supported by natural teeth [9]. Their uniqueness are more related to their potentially significant negative impact on oral sensory input during function and on the prosthetic bulk required. Because of this, removable dentures may present a challenge to accommodation, of which patients should be made aware during the treatment planning stage [31]. In case of partial edentulism, rehabilitation of the oral function can be obtained with fixed or removable prosthodontics [24].

When a removable partial denture is used to replace missing posterior teeth especially when distal abutments are absent, any additional missing anterior teeth are replaced by means of fixed restorations rather than included in the removable partial denture [6]. In case of distal extension, anteroposterior rotational action might occur as a result of the addition of an anterior segment to the denture. The shape and function of the mouth following a disruption caused by the loss of teeth are restored by wearing removable partial dentures, but this may also contribute to various problems. Removable partial dentures have the physical, chemical, and biological adverse effects which can cause caries of abutment teeth [27].

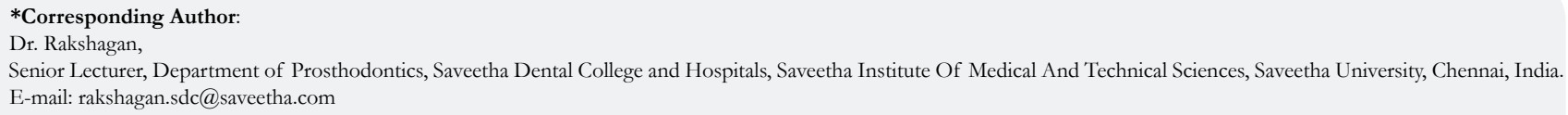

Copyright: Rakshagan ${ }^{\circ}$ 2020. This is an open-access article distributed under the terms of the Creative Commons Attribution License, which permits unrestricted use, distribution and reproduction in any medium, provided the original author and source are credited. 
Wearing a removable partial denture complicates the oral environment and restricts the flow of food and the self-cleansing action of the buccal mucosa and tongue resulting in accumulation of the dental plaque on the prosthesis and surrounding tissue [20, $22,15]$. Reports of removable partial dentures indicated that the health of the remaining dentition and surrounding oral tissues often gets deteriorated. In a study that evaluated the need for repair of an abutment tooth as the indicator of failure, the success rates of conventional removable partial dentures were $40 \%$ at 5 years and $20 \%$ at 10 years [29].

Patient satisfaction is a prime concern in construction of removable partial dentures. Improving mastication, speech, and aesthetics are some of the main goals during denture designing [16]. A typical removable partial denture consists of a cast framework with an acrylic base and replacement teeth. Preservation of the remaining structures is also one of the main objectives of the removable partial dentures [30].

Thus the aim of the present study is to evaluate the indications or feasibility of the removable partial dentures in Saveetha Dental College.

\section{Materials and Methods}

\section{Study setting}

In this study, patient records from the department of prosthodontics, Saveetha Dental College, Chennai were extracted from June 2019 to March 2020. The approval for this university setting study was obtained from the Institutional Ethics Board. The sample size for this study was 100 patients wearing removable partial dentures. The study was reviewed by 2 reviewers and was cross verified. Records with a clinical diagnosis of removable dentures were selected.

\section{Data Collection and Tabulation}

The case records for 89,000 partially and completely edentulous patients were retrieved and revised for the analysis. Clinical data of each patient wearing RPDs were selected from Dias software. Patients wearing cast partial dentures and implant supported dentures were excluded. The data of the patients wearing removable partial dentures were classified based on age and gender. All patients were informed about the study protocol and informed consents were obtained.

\section{Statistical Analysis}

After further verification of data by an external reviewer, it was imported to the SPSS software by IBM for statistical analysis. Descriptive statistical methods (means, standard deviation, and percentages) were employed in the analysis. The records are set in a logical order. Chi-Square Test was used to detect the significance between age and diagnosis of removable denture patients.

\section{Result And Discussion}

A total of 3725 partial edentulism patients were scrutinized out of total 86,000 patients. Out of the 3725 patients, $3285(88.19 \%)$ patients were wearing RPDs and $440(11.19 \%)$ patients did not undergo any RPD treatment. [Figure 1] Out of the 3285 patients, 1857 (49.85\%) male patients and 1428 (38.34\%) female patients were wearing RPDs. Males showed a higher prevalence of having removable partial dentures than females. [Figure 2] The least age group affected was the 10-30 years group. Design, materials, ease of repair, patient education, and follow-up for RPD treatment all had a significant impact on treatment success.

Figure 1. This graph represents the distribution of no.of removable partial denture patients with no.of without removable partial denture patients. Blue denotes patients with RPDs and red denotes patient without RPDs. It shows that 3285 $(88.19 \%)$ patients had RPD treatment and 440 (11.81\%) patients did not undergo RPD treatment.

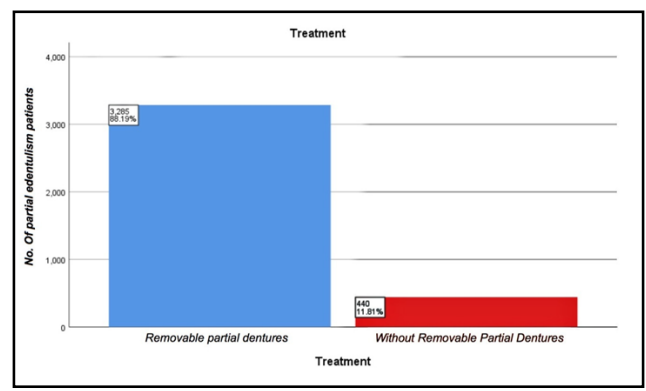

Figure 2. This graph represents the frequency of gender distribution of removable partial denture patients and without removable partial denture patients. $\mathrm{X}$ axis denotes the gender distribution and $\mathrm{Y}$ axis denotes the count of patients. Blue denotes the patients which had RPD treatment, and red denotes the patients without RPD treatment. The Male gender has more prevalence in wearing RPDs. Analysed by Chi-square test, $\mathrm{p}$ value obtained is 0.156 which is not significant, $(\mathrm{p}<0.05)$. Though it is statistically not significant, we found that $49.85 \%$ of male patients and $38.34 \%$ of female patients underwent RPD treatment.

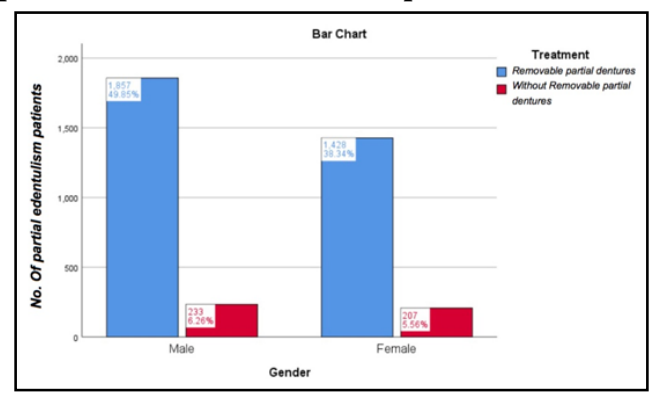


Hence, male patients showed a higher prevalence of removable dentures in Saveetha Dental College. Results were made into bar charts and compared with previous studies.

According to the results of the present study, $12 \%$ difference was found between the genders, with more male patients (56\%) [19]. Other studies demonstrated a similar trend. Some authors evaluated the frequency, distribution and localization of fixed prosthesis and observed that $60 \%$ of it was for men [14].

On the contrary, Abdurahiman VT et al. did not notice a significant gender difference in appearance of partial edentulism [1]. Similarly, Abdel Rahman HK et al. showed that gender does not have a significant relationship with the prevalence of different classes of partial edentulism [28].

Male patients are more predominant in dental offices due to their exposure to various habits like smoking and alcohol. Considering that, men visit dentists more frequently, they are susceptible to exodontia and rehabilitation procedures, which is in agreement with the results of the present study [17]. Women avoid dental and medical examinations due to different work schedules, socioeconomic factors and culture [4].

Age by itself is an imprecise guideline in the assessment of older patients. Of much greater importance is the effect that illness may have had on the ageing process. For this reason a detailed medical history is essential and should include a full list of any prescribed medications $[13,34]$.

Our study shows that elderly patients are more susceptible to wearing removable partial dentures. Elderly patients can have teeth replaced with removable or fixed prostheses supported by mucosa, teeth, or implants. Age does not influence which option is the best [3].

The treatment that elderly patients should receive can be clarified by ranking them in three categories - (1) the health of the patient (2) the health of their dentition and (3) the health of their finances. Biographical research revealed that there is no standard for stratification by age, which influences a comparison between data [33]. Other studies showed similar data. A literature review conducted about the prevalence of dentures concluded that most of the patients wearing removable dentures were older and presented poor social-economic situations and low educational levels $[32,23]$. Most of the patients needed up to three follow-ups after RPD insertion. About $12.8 \%$ of the patients did not attend the follow-ups in previous studies.

The state of health is an important factor to consider while deciding whether to advise the provision of removable partial dentures or not. Progressive infirmity or debility can have an adverse effect on the capacity to adapt and may explain the difficulty that some patients have in coming to terms with dentures, particularly if they have had no previous denture wearing experience $[10,12,5]$. It is thus very important to determine what, if any, improvement in the state of health can be expected. The effect that health factors may have on the ability of patients to attend for treatment and subsequent maintenance must also be considered [26, 25].

The removable partial dentures provide not only definitive reha- bilitation but also social restoration even when used provisionally during complex treatments with implant supported fixed prostheses. Some implant supported treatments require a longer period of osseointegration, which may be solved by wearing removable dentures [2]. The length of edentulous, periodontal support, cross-arch stabilization, abutment teeth are for removable partial dentures.

It is important to assess the degree to which patients are motivated to wear removable partial dentures. It is not uncommon to find that the request for prosthetic treatment comes from colleagues or family members, particularly if they feel that the patient's recovery from severe illness is being hampered by inadequate dentition. Unless patients themselves wish to have removable partial dentures and unless a high standard of plaque control can be achieved either by the patients themselves or by the carers, treatment is unlikely to be successful.

\section{Conclusion}

Males are more prevalent for removable partial dentures as they are exposed to more deleterious habits. Elderly people should be educated more on how to maintain proper oral hygiene. Variations in the construction of removable partial denture design concepts with international studies reflect the influence of teaching philosophy and diversity of faculty member's backgrounds.

The distribution of partially edentulousness revealed the impact of the general structure of tooth loss, which can be modified depending on the patient's demand and socio-economic status. Clinicians need to avail themselves fully of basic removable dentures design principles concerning the most commonly encountered classes of removable dentures. Hence, removable partial dentures are still used in all age groups, including young adults. Previous research studies highlighted that a large number of removable dentures had defects. Further research should be conducted in India, to know and involve further developing ideas to decrease the prevalence of removable partial dentures among all age groups.

\section{References}

[1]. Abdurahiman VT, Abdul Khader M, Sanju John Jolly. Frequency of partial edentulism and awareness to restore the same: a cross sectional study in the age group of 18-25 years among kerala student population. J Indian Prosthodont Soc. 2013 Dec;13(4):461-5. PubmedPMID: 24431776.

[2]. Ajay R, Suma K, Ali SA, Kumar Sivakumar JS, Rakshagan V, Devaki V, et al. Effect of Surface Modifications on the Retention of Cement-retained Implant Crowns under Fatigue Loads: An In vitro Study. J Pharm Bioallied Sci. 2017 Nov;9(Suppl 1):S154-S160. Pubmed PMID: 29284956.

[3]. Ashok V, Nallaswamy D, Benazir Begum S, Nesappan T. Lip Bumper Prosthesis for an Acromegaly Patient: A Clinical Report. J Indian Prosthodont Soc. 2014 Dec;14(Suppl 1):279-82. PubmedPMID: 26199531.

[4]. Ashok V, Suvitha S. Awareness of all ceramic restoration in rural population. Research Journal of Pharmacy and Technology. 2016 Oct 28;9(10):1691-3.

[5]. Basha FY, Ganapathy D, Venugopalan S. Oral hygiene status among pregnant women. Research Journal of Pharmacy and Technology. 2018 Jul 31;11(7):3099-102.

[6]. Benson D, Spolsky VW. A clinical evaluation of removable partial dentures with I-bar retainers. Part I. J Prosthet Dent. 1979 Mar;41(3):246-54. PubmedPMID: 368315 .

[7]. Bergman B, Hugoson A, Olsson CO. Caries, periodontal and prosthetic findings in patients with removable partial dentures: a ten-year longitudinal study. J Prosthet Dent. 1982 Nov;48(5):506-14. PubmedPMID: 6754910.

[8]. Bergman B, Hugoson A, Olsson CO. A 25 year longitudinal study of patients treated with removable partial dentures. J Oral Rehabil. 1995 Aug;22(8):595-9. PubmedPMID: 7472731. 
[9]. Budtz-Jorgensen E, Bochet G. Alternate framework designs for removable partial dentures. The Journal of prosthetic dentistry. 1998 Jul 1;80(1):58-66.

[10]. CARLSSON GE, HEDEGARD B, KOIVUMAA KK. Studies in partial dental prosthesis. II. An investigation of mandibular partial dentures with double extension saddles. ActaOdontol Scand. 1961 Aug;19:215-37. PubmedPMID: 13876662.

[11]. Cosme DC, Baldisserotto SM, Fernandes Ede L, Rivaldo EG, Rosing CK, Shinkai RS. Functional evaluation of oral rehabilitation with removable partial dentures after five years. J Appl Oral Sci. 2006 Apr;14(2):111-6. PubmedPMID: 19089041

[12]. Curtis DA, Curtis TA, Wagnild GW, Finzen FC. Incidence of various classes of removable partial dentures. J Prosthet Dent. 1992 May;67(5):664-7. PubmedPMID: 1527752.

[13]. Douglass CW, Watson AJ. Future needs for fixed and removable partial dentures in the United States. J Prosthet Dent. 2002 Jan;87(1):9-14. PubmedPMID: 11807477.

[14]. Drukker W, Parsons FM, Maher JF, editors. Replacement of renal function by dialysis: a textbook of dialysis. Springer Science \& Business Media; 2012 Dec 6.

[15]. Duraisamy R, Krishnan CS, Ramasubramanian H, Sampathkumar J, Mariappan S, NavarasampattiSivaprakasam A. Compatibility of Nonoriginal Abutments With Implants: Evaluation of Microgap at the Implant-Abutment Interface, With Original and Nonoriginal Abutments. Implant Dent. 2019 Jun;28(3):289-295. PubmedPMID: 31124826.

[16]. Ganapathy D, Sathyamoorthy A, Ranganathan H, Murthykumar K. Effect of Resin Bonded Luting Agents Influencing Marginal Discrepancy in All Ceramic Complete Veneer Crowns. J ClinDiagn Res. 2016 Dec;10(12):ZC67ZC70. PubmedPMID: 28209008.

[17]. Ganapathy DM, Kannan A, Venugopalan S. Effect of coated surfaces influencing screw loosening in implants: A systematic review and meta-analysis. World Journal of Dentistry. 2017 Nov;8(6):496-502.

[18]. Harvey WL, Hoffman W Jr. Ten-year study of trends in removable prosthodontic service. J Prosthet Dent. 1989 Dec;62(6):644-6. PubmedPMID: 2585322.

[19]. Ranganathan H, Ganapathy DM, Jain AR. Cervical and Incisal Marginal Discrepancy in Ceramic Laminate Veneering Materials: A SEM Analysis. ContempClin Dent. 2017 Apr-Jun;8(2):272-278. PubmedPMID: 28839415.

[20]. JAIN AR, NALLASWAMY D, ARIGA P. Determination of Correlation of Width of Maxillary Anterior Teeth with Extraoral Factor (Interpupillary Width) in Indian Population. Journal of Clinical \& Diagnostic Research. 2019 Jul $1 ; 13(7)$
[21]. Jay M. Supernormal: The untold story of adversity and resilience. Twelve; 2017 Nov 14.

[22]. Jyothi S, Robin PK, Ganapathy D. Periodontal health status of three different groups wearing temporary partial denture. Research Journal of Pharmacy and Technology. 2017 Dec 1;10(12):4339-42.

[23]. Kannan A, Venugopalan S. A systematic review on the effect of use of impregnated retraction cords on gingiva. Research Journal of Pharmacy and Technology. 2018 May 30;11(5):2121-6.

[24]. Lechner SK, Thomas GA. Removable partial denture design: importance of clinical variables. Eur J ProsthodontRestor Dent. 1994 Mar;2(3):127-9. PubmedPMID: 7920405.

[25]. Liedberg B, Stoltze K, Owall B. The masticatory handicap of wearing removable dentures in elderly men. Gerodontology. 2005 Mar;22(1):10-6. PubmedPMID: 15747893.

[26]. Niarchou AP, Ntala PC, Karamanoli EP, Polyzois GL, Frangou MJ. Partial edentulism and removable partial denture design in a dental school population: a survey in Greece. Gerodontology. 2011 Sep;28(3):177-83. PubmedPMID: 21284711.

[27]. Sadig WM, Idowu AT. Removable partial denture design: a study of a selected population in Saudi Arabia. J Contemp Dent Pract. 2002 Nov 15;3(4):40-53. PubmedPMID: 12444401.

[28]. Abdel-Rahman HK, Tahir CD, Saleh MM. Incidence of partial edentulism and its relation with age and gender. Zanco Journal of Medical Sciences (Zanco J Med Sci). 2013;17(2):463-70

[29]. Selvan SR, Ganapathy D. Efficacy of fifth generation cephalosporins against methicillin-resistant Staphylococcus aureus-A review. Research Journal of Pharmacy and Technology. 2016 Oct 28;9(10):1815-8.

[30]. Subasree S, Murthykumar K. Effect of aloe vera in oral health-A review. Research Journal of Pharmacy and Technology. 2016 May 1;9(5):609.

[31]. Vanzeveren C, D'Hoore W, Bercy P, Leloup G. Treatment with removable partial dentures: a longitudinal study. Part II. J Oral Rehabil. 2003 May;30(5):459-69. PubmedPMID: 12752924.

[32]. Venugopalan S, Ariga P, Aggarwal P, Viswanath A. Magnetically retained silicone facial prosthesis. Niger J ClinPract. 2014 Mar-Apr;17(2):260-4. PubmedPMID: 24553044

[33]. Vijayalakshmi B, Ganapathy D. Medical management of cellulitis. Research Journal of Pharmacy and Technology. 2016 Nov 28;9(11):2067-70.

[34]. Wöstmann B, Budtz-Jørgensen E, Jepson N, Mushimoto E, Palmqvist S, Sofou A, et al. Indications for removable partial dentures: a literature review. Int J Prosthodont. 2005 Mar-Apr;18(2):139-45. PubmedPMID: 15889662. 